\title{
Computing and Computer Science in the Soviet Baltic Region
}

\author{
Enn Tyugu \\ Institute of Cybernetics of Tallinn University of Technology \\ tyuguaieee.org
}

\begin{abstract}
This work includes references at events, people, and trends in computing in the three Baltic States: Latvia, Lithuania, and Estonia during their Soviet period. The Soviet computing science and practice could be divided into league A and league B. The first was for defense industry and power structures, the second for wide public. Although the Baltic computing belonged in essence to the league $\mathrm{B}$, its scientific results were on the level with the league $\mathrm{A}$.
\end{abstract}

Keywords: Baltic computing, computing history, Soviet computing.

\section{Introduction}

The title of the work sets the period of the subject - until fall of the Soviet Union, practically in the end of the 1980s. The geographical focus is on three Baltic republics: Latvia, Lithuania, Estonia, and to some extent on Leningrad as well. My personal experiences relate to Estonian computer engineering and science. Therefore, we will consider computing in this small country in more detail, including even some relations with Danish, Finnish, Norwegian, and Swedish computer scientists.

Computing in the Soviet Union was considered as a part of cybernetics - a "capitalist pseudoscience" in 1950s; hence, publicly was nonexistent although they used computers by physicists and space engineers. Nikita Khruschov in 1958 suddenly decided that the country urgently needed a larger number of computer engineers and mathematicians with computing skills for defense and space industry. Several hundreds young physicists, mathematicians and electronic engineers were reeducated in two years in Leningrad Technical University and Moscow Institute of Energy providing them as good education in computing as it was possible in those days. It may be interesting to look at the computer science curriculum of those days.

Below is the complete list of courses together with number of hours of supervised work - lectures and applications (taken from the course list of the author) given to the computer specialists in Moscow and Leningrad.

Ordinary differential equations -90

Algebra - 90

Functions of a complex variable -90

Probability theory and statistics -105

Partial differential equations -30

Numeric methods -60 
Programming -55

Control theory and tracking systems - 204

Semiconductors and magnetic elements -60

Electronic devices - 150

Theory of electric circuits -60

Arithmetic and logic of computers - 45

Theory and design of analog computers $-90+180$

Theory and design of digital computers $-108+206$

The last two courses included many hours of practical work (180 and 206 respectively). One can notice the absence of logic and discrete mathematics, although the curriculum was rather mathematically oriented. In addition, they only offered a single rather short course in programming. The education was strongly oriented at hardware design and applied mathematics, because they knew little about programming. The term "software" did not exist yet.

\section{First Years of Baltic Computing}

Among the graduates of the classes given in Moscow and Leningrad were ten Estonians and even a larger number of Lithuanians who then returned to their countries. This was the first source of expertise in computing in the Soviet Baltic countries. Another input in this branch came from some enthusiastic mathematicians of Tartu University and Riga. At the end of the 1950s, Ülo Kaasik at the University of Tartu initiated mathematically oriented computer science education and its first graduates came in 1960. Leo Võhandu, who later moved to Tallinn Technical University, soon joined Ülo Kaasik in Tartu.

Lithuanian computing graduates from the Leningrad Technical University became the key players in a newly founded computer plant in Vilnius, and therefore they were not immediately visible in science. The computer plant, later known under the name "Sigma", became one of the major computing equipment producers for non-military computer systems. The Ruta 110 computer designed and produced in "Sigma" was widely used in the Soviet Union. There were two Lithuanian centers of computer science research - one in Vilnius and another in Kaunas. The leader of the center in Kaunas became Henrikas Pranevičius who graduated Kaunas Polytechnic Institute as a radio engineer in 1964. People know him for his works in formal methods and simulation applied to distributed systems. Albertas Caplinskas and Olegas Vasilecas worked in the field of knowledge-based software in Vilnius.

A Latvian young mathematician Janis Bardins from Riga was a graduate student of Boris Trakhtenbrot in Novosibirsk, a well-known expert in automata theory in the sixties. Barzdins became the leader of computer science in Latvia. Janis Barzdins obtained fundamental results in inductive inference, and later applied his experiences in inductive program synthesis. Besides these works, they did more research on the border of logic and computing at the University of Latvia. An active group of researcher in computer science grew around Janis Barzdins, including I. Etmane, R. Freivalds and others. Their research focused on logic and included various methods of synthesis of programs. Another research direction in the University of Latvia was automatic test case generation (Janis Bicevskis, Audris Kalnins, Juris Borzovs). Interesting research 
was carried out in the Riga Technical University in the field of fuzzy sets (Janis Osis had spent a year with Zadeh at Berkeley University) and system analysis by means of topological models.

Early Estonian computing was influenced by the fact that Institute of Cybernetics was founded in Tallinn in 1960, primarily by initiative of Nikolai Alumäe, who needed computers for his research in dynamics of thin shells (submarine hulls). This institute was the place where they built the first digital computer M-3 in Estonia in 1960. Its original design had come from Minsk, but they improved it significantly by adding a core memory instead of a much slower magnetic drum. This increased the performance of the computer considerably. The Institute of Cybernetics became a leading research center in computer science and computer applications in the Soviet Baltic region.

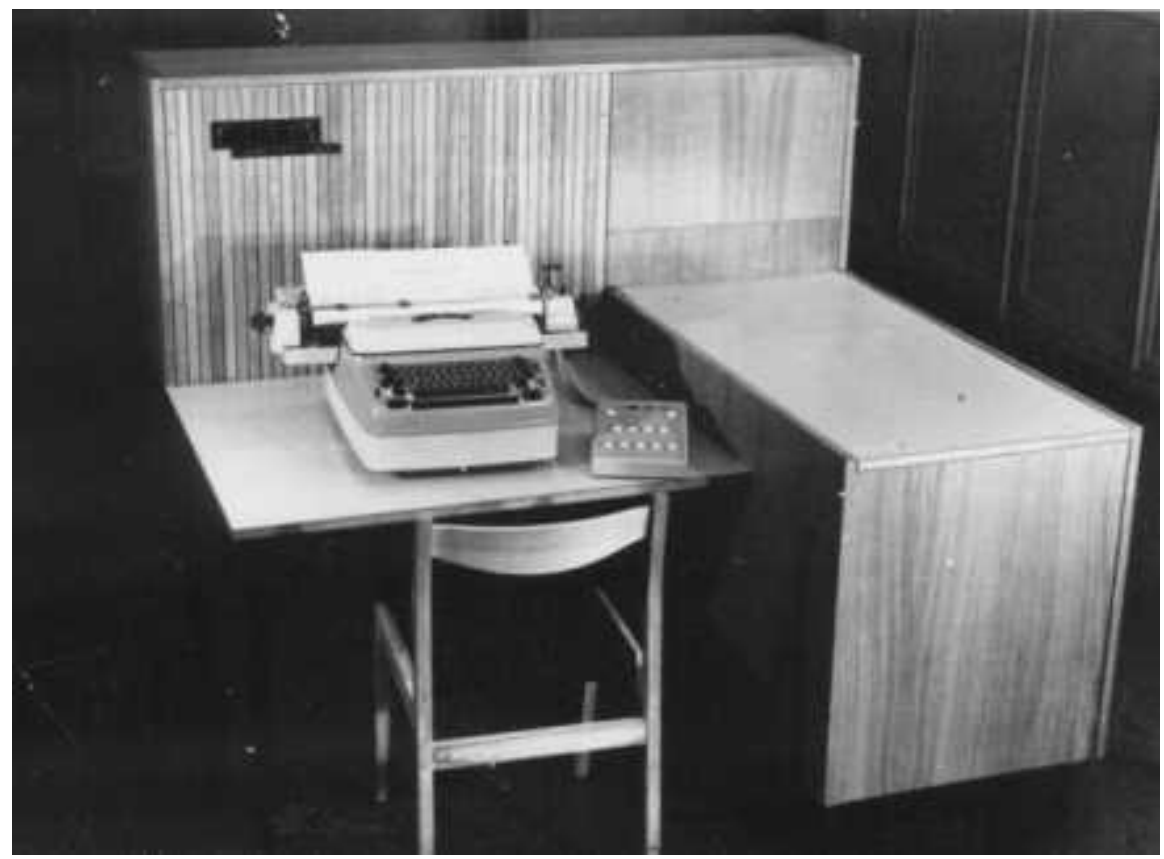

Fig. 1. STEM minicomputer in 1964

The first minicomputer called STEM, see Figure 1, was designed and built very early in Estonia - in years 1962 - 1964 at the Electrotechnical Research Institute in Tallinn. It had 16-bit words, small core memory, large ROM, and interactive inputoutput through electric typewriter. This computer was unusually reliable for those days. They used it in a technology department of Putilov factory in Leningrad and not in a computing center, because it did not require technical support around the clock that was then a common requirement. They used STEM in Putilov factory for engineering calculations during many years. More computers of this kind, but on different component base they built them for other large plants in the Soviet Union. 


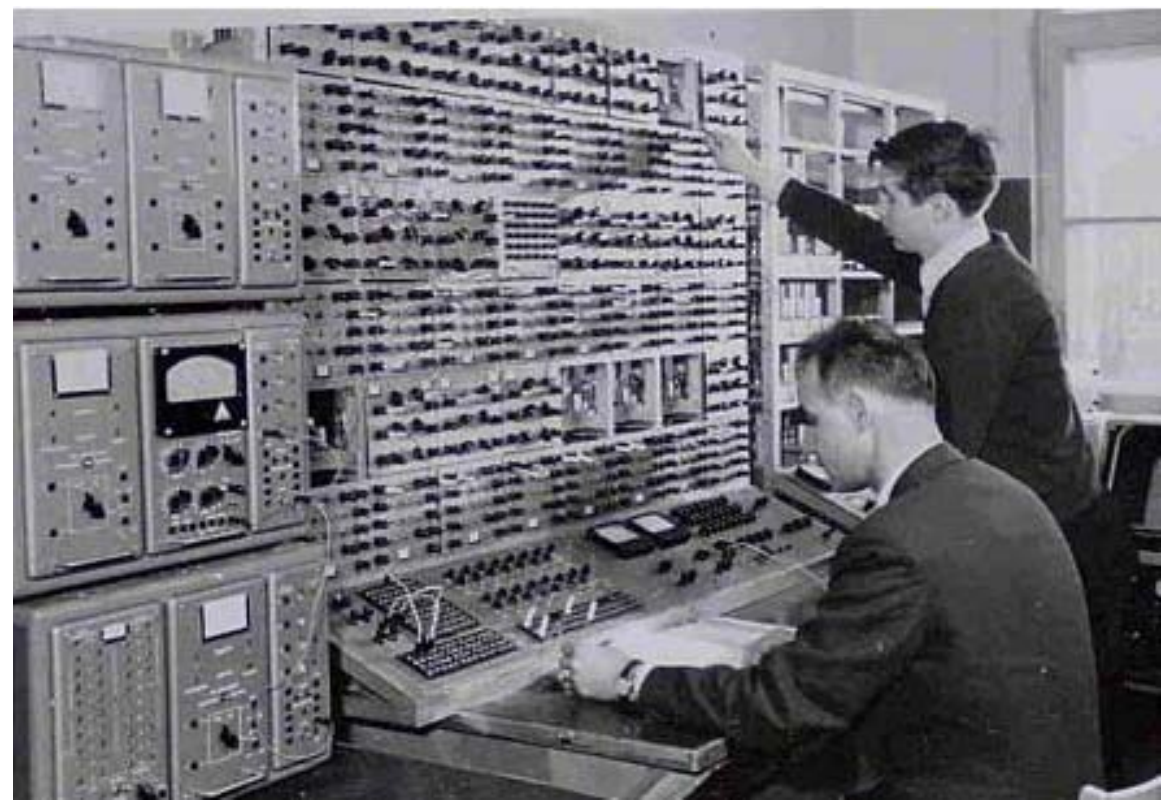

Fig. 2. The first analog computer built in Estonia

Neither the M-3 nor the STEM were the first computers built in Estonia. The very first was an analog computer designed and built in 1959 by electrical engineers of the Tallinn Technical University for the purpose of modeling and simulation of large power networks. This computer appears in Figure 2.

\section{Computer Science in Estonia}

Early research in computer science in Estonia was mainly in programming languages. This was language design and syntactic analysis. Malle Kotli developed a language called MALGOL (modular Algol) and it was widely used on popular Minsk computers. Mati Tombak became the leader of research in syntactic analysis, and he supervised a number of $\mathrm{Ph}$.D. theses in this area. Success in syntactic approach inhibited deeper interest in semantics of computations for years. The situation changed in the end of the 1970s, when Merik Meriste and Jaan Penjam proposed new efficient methods of implementation of attribute semantics, and wider interest in automatic program construction appeared.

In the beginning of 1970s, Wilhelm Kracht introduced automata theory in his seminars to young scientists. Soon it gave output in the form of Ph.D. theses on decomposition of automata (Gabriel Jakobson, Andres Keevallik, Paul Leis). This research domain became practically widely recognized many years later, when fast computers and new challenges in chip design appeared. Many theses were written in the Institute of Cybernetics on the border between computer science, numeric methods and statistics. Leaders from the math side were Ivar Petersen and Sulev Ulm. A brief survey of research topics in 1970s and 1980s in Estonia is as follows. 
o Research in databases (Ain Isotamm, Anne Villems, Enn Tyugu, Ahto Kalja, Hele-Mai Haav).

o Control theory and computer control (Ülle Kotta, Raul Tavast, Leo Mõtus).

o Systolic algorithms and FFT (Ilmar Arro, Toomas Plaks).

o Synthesis of programs (Enn Tõugu, Grigori Mints).

- Attribute grammars (Jaan Penjam, Merik Meriste).

○ Expert systems and knowledge representation (Jaak Tepandi, Enn Tõugu, Mare Koit).

○ Logic, in particular, proof theory, realizability, model checking (Grigori Mints, Tanel Tammet, Sergei Tupailo).

o Software environments (Boris Tamm, Jaan Pruuden, Mihail Matskin, Aleksander Shmundak).

o Test generation (Raimund Ubar).

\section{Software Tools and Applications}

On the software side, the first remarkable result was the development of a language and environment SAP-2 for numeric control of machine tools in Estonia in the beginning of the 1960s. The system SAP-2 was introduced in the Soviet aviation industry and gave a good position for its main developer Boris Tamm in the Soviet computing. Another group of researchers (Enn Tyugu et al) developed and applied in industry a modular programming environment SMP in the end of 1960s. This became a starting point for research in software engineering here, because SMP supported a well-defined software technology and documentation. This research direction was continued by development of structural synthesis of programs and its implementation in several software tools (PRIZ, MicroPRIZ, NUT). They used these tools in the development of $\mathrm{CAD} / \mathrm{CAM}$ applications. The first engineering applications were optimization programs for machine tools such as cutting conditions and processing time for the Putilov plant in Leningrad in the 1960s. They developed larger applications for Elektrosila plant in Leningrad and rocket engines plant in Dnepropetrovsk in the 1970s. They also developed numerous applications in power semiconductor design and technology for Tallinn Electrotechnical plant in the 1980s under supervision of Valeri Grigorenko.

On the data processing side, there was an information system project for a large wholesale warehouse of Estonian Consumers Cooperative Society (ETKVL) that was completed already in the 1960s. The ETKVL administration well supported this project and it attracted good software developers due to strong working conditions and salaries; it became a success case of a large information system development in the Soviet Union. Another long-lasting and quite successful information technology project in Estonia was computer control of chemical processes in the oil shale chemistry, done by researchers of the Institute of Cybernetics and supervised by Raul Tavast in 1970s.

\section{Computer Design Office}

An important milestone of computing in Estonia was founding of the Computer Design Office (EKTA) of the Institute of Cybernetics in 1976. It had been a dream of Harry Tani, an outstanding computer engineer, who became the director of research 
of EKTA. Due to his personal contacts with German engineers as well as with researchers in the Soviet Union, EKTA got advanced microprocessors and printed circuits technology, and it evolved into a leading center in design and application of microprocessor systems in the Soviet Union. The Computer Design office designed and manufactured a small number of personal computers "Juku" for Estonian schools in 1988. It was a dream that success of this project would have the influence on education in Estonia comparable to the publication of bible in the native language in the eighteenth century. Unfortunately, manufacturing of these computers in larger numbers was impossible because of shortage of reliable components and devices like disk drives in the Soviet Union.

\section{Computing in Leningrad}

Leningrad had strong computer science and engineering education in many universities. However, paradoxically, not too many widely known results in computer science came out. Probably, the main reason was the confidentiality of many works performed in military institutions of this city. This kind of institution was, for example, a Construction Bureau-2 (KB-2) of Electronic Technology headed by Philip Staros (Alfred Sarant), who developed the lightweight computers for space, and it was the first to develop pocket calculators in the Eastern Block in seventies. Still, we remember a number of very interesting and pleasant people from Leningrad closely related to Estonia. Svjatoslav Lavrov and Viktor Varshawski were most supportive to young Estonian researchers. A special relation was between the Institute of Cybernetics and Leningrad Division of Mathematical Institute of the Soviet Academy of Sciences (LOMI). A strict constructivist logician Nikolai Shanin and his group had a strong influence on Estonian computer science. The members of this group Sergei Maslov (proof theory), Anatol Slisenko (recursion theory), Grigori Mints (proof theory), Yuri Matijasevich (algebra and logic) have all strongly influenced Estonian theoretical computer scientists. Grigori Mints worked as a researcher in the Institute of Cybernetics for ten years before taking a position of professor at Stanford University in the USA.

\section{Western Contacts}

Although Estonia was behind the iron curtain, the country had better scientific contacts with the West than most parts of the Soviet Union. There was a special agreement on scientific cooperation between the Soviet Union and Finland in the field of computer science. Estonian scientists mainly handled this without interference from Moscow, and beginning from 1988, it became an Estonian-Finnish agreement. Finnish scientists (Reino Kurki-Suonio, Markku Syrjänen, Hannu Jaakkola, Timo Järvi, Esko Ukkonen and many others) were frequent visitors to Estonia. Jaak Henno received a postdoc position with A. Salomaa's group in 1976; he worked on the complexity of multiplace functions and even published together with Salomaa. Good contacts were established with Denmark (Dines Björner) and Sweden (Bengt Nordström's group and Jan Smith in particular, Per Martin-Löf) in the 1980s. Eric Sandevall from Linköping sent a source code of Interlisp when it was a popular AI programming tool to the Institute of Cybernetics, and helped in this way the researchers in artificial intelligence to become 
a part of international AI community. Estonia became a meeting place of western and eastern computer scientists where they held numerous meetings because it was easily accessible from both sides, especially by ferry from Helsinki from the West.

\section{Two Leagues of the Soviet Computing}

Speaking about the computer science in the context of the Soviet Union, one has to bear in mind that it had been from the very beginning closely related to the Soviet power structures (defense industry and military people). This continued even later when usage of data processing became widely available. Due to shortage of resources, the computing industry and science could be divided roughly into league A that had better resources (including practically unlimited number of people in the research groups) and served the power structures, and league B that had shortage of resources, but more openness and some freedom of research. Attributes of league A were computers M-20, BESM-4, BESM-6 and later Elbrus. League B had the popular Minsk computers, and from the end of the 1970s, also Rjad (in Russian ES) computers that were copied from the IBM 360/370 mainframes. (Computers mattered in those days, because software was very much dependent on a hardware platform.)

Estonian computer science belonged to the league B, especially; there was no BESM computer in Estonia except in some military institutions that were completely closed to researchers. It seems now that this was a clever decision of the leaders of local institutes, in particular, of Boris Tamm and Nikolai Alumäe who were in the position of influencing the decision-making on high level. This gave more freedom in communication with West and more openness. However, already from the beginning of seventies, Estonian researchers established good contacts with the researchers from league A. This happened due to regular winter and summer schools organized in summer and winter resorts of Estonia jointly by universities and the Academy of Sciences with good programs and participation of research leaders of most of the league A groups. Finally, we started feeling like belonging to the league A, except that we did not have the right computers. Finally, they made a decision at the end of the 1970s that we should try to obtain a new Soviet supercomputer Elbrus-1. It happened that Elbrus-1 with serial number 10 was planned for delivery to the Institute of Cybernetics in 1979-1980. They also provided financing - almost 11 million rubles. Only the computer did not appear in time. It did not appear even a year later, and became operational only in 1987. Then we had already workstations that made simple arithmetic operations with short numbers faster than Elbrus-1 with its long words and very complex CPU.

\section{The Start Project}

START was a large computer hardware and software project in the Soviet Union in the 1980s where Estonian researchers actively participated. This project was initiated by researchers from Moscow (Viktor Brjabrin), Novosibirsk (Vadim Kotov and Aleksandr Narinyani) and Tallinn (Enn Tyugu) as a late response to the Japanese Fifth Generation Computer Project. There had been some attempts to establish a cooperative fifth generation computer project in the Eastern Block as a response to the respective Japanese project. These attempts were not successful, and this gave an opportunity for the researchers with good contacts to Guri Marchuk (the Chairman of the State Committee 
for Science and Technology and President of the Academy of Sciences) to propose the project START. Its intent was a completely open (non-secret) virtual research enterprise, contrary to several other similar Soviet projects. The aim of the initiators of the project was obviously to get better resources for testing their ideas in computer architecture (Vadim Kotov), software (Viktor Brjabrin) and artificial intelligence (Aleksandr Narinyani, Enn Tyugu). Due to the direct support from the president of the Soviet Academy of Sciences, the project enjoyed good resources. A special issue of the Communications of the ACM [1] described the outcome of the project START. About thirty persons participated in the project from the Estonian side. The main results in Tallinn were a workstation PIRS with a 32-bit processor KRONOS (processor developed in Novosibirsk), including software of the workstation (C compiler, UNIX installation, and a windowing system) and an intelligent programming environment Nut written in C. Later on, the Nut system appeared on many workstations and PCs; they used it for the simulation of large projects such as hydraulic systems and the radar coverage of Estonia.

\section{Restructuring of the Research}

The START project gave some resources to researchers in the end of eighties, when the international embargo on hardware and software was very restrictive. In addition, EKTA had its contacts with partners from West. This helped the research in computer science to survive until the end of the Soviet Union, when the situation changed abruptly. This is visible from the Figure 3 where one sees almost constant growth of the number of employees of Institute of Cybernetics and EKTA until the collapse of the Soviet Union [2]. The only disruption of the linear growth is from building up EKTA in 1976-1978.

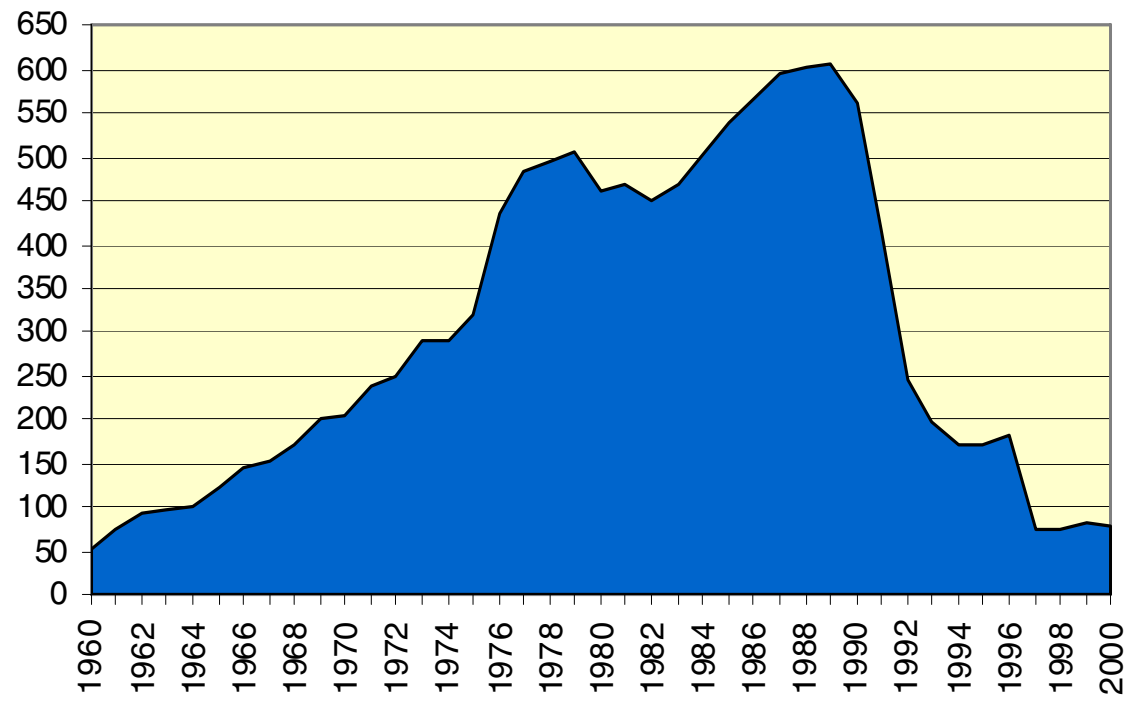

Fig. 3. Number of employees in the Institute of Cybernetics and EKTA 
What happened later is another story. Briefly, the banks and other rapidly developing enterprises attracted clever people, and a number of researchers with good credentials left to other countries. EKTA became a small independent high-tech company; additionally, some other application-oriented groups of the institute had left. The institute has been incorporated in the Tallinn University of Technology, and it continues with almost constant number of employees, including some very bright young researchers, as a typical Western research center now.

\section{References}

[1] Communications of the ACM 34(6), 46-59 (1991)

[2] Institute of Cybernetics in changing times (In Estonian: Küberneetika Instituut muutuvas ajas) Institute of Cybernetics, Tallinn (2000) ISBN 9985-894-25-1 